\title{
The Impact of Technology Selection on Innovation Success and Organizational Performance
}

\author{
Shengbin Hao, Bo Yu \\ Business Management Department, Harbin Institute of Technology, Harbin, China. \\ Email: haoshengbin@yahoo.cn,yub@hit.edu.cn \\ Received October14 $4^{\text {th }}, 2011$; revised November $16^{\text {th }}, 2011$; accepted November $24^{\text {th }}, 2011$.
}

\begin{abstract}
This paper is to analyze the impact of a company's technology selection on its innovation success and organizational performance. Technological capability enables a company to add value to products and processes, and its impact on innovation success has been examined. Apart from technological capability, a company also needs technology management capability to manage technological resources effectively and efficiently. In this paper, we develop a theoretical model for implementation of technology selection, consisting of five elements: technology selection, technological capability, technology management capability, innovation success and organizational performance. The model is empirically tested using the data of 120 Chinese companies acquired by interviews and surveys. The results indicate that a company's technology selection has no direct impact on innovation success; technology selection has a significant positive impact on technological capability and technology management capability, which, in turn, have a significant positive impact on innovation success; innovation success has a significant positive impact on organizational performance.
\end{abstract}

Keywords: Technology Selection, Technological Capability, Technology Management Capability, Innovation Success, Organizational Performance

\section{Introduction}

As technology innovation can help the company to build competitive advantage through making more competitive products and services and more effective processes, or creating completely new business, both academic researchers and managers have been paying much attention to the explanation of innovation success. Due to increasing innovation costs, decreasing innovation cycles and increasing technology complexity, the achievement of a company's innovation success has lately received renewed attention. Researchers can be roughly divided into two camps: one group is describing the external factors for innovation success, most researchers of this group are analyzing the impact of innovation network [1-3], and examining innovations as the result of collaborations between various companies, the innovation process can involve collaboration with many different types of partners, each offering significant resources [4-7]. The other group is committed to analyzing the internal factors, for example, analyzing the business strategy, corporate culture, teams collaboration and technological capability [8-10].
Given these two areas for achieving innovation success, we need to analyze the underlying capabilities on which their impact is based. Several studies have looked into the role of technological capability played in innovation success [11-12], and treat technological capability as the core of innovation capability. However, apart from technological capability, companies also need other capabilities to achieve innovation success, such as managerial capabilities for promoting the efficiency of technological resources utilization [13-16]. Among these managerial capabilities, technology management capability, may affect innovation success a lot, and it has begun to receive the researchers' attention. Besides, companies need to make technology selection decisions and introduce new technologies continuously, in order to develop new products to meet the changing market needs and acquire the new market growth point, which will help companies achieve the improvement and promotion of organizational performance. There is a positive guiding relationship among technology selection, technology innovation and organizational performance. Technology selection, especially technology strategy selection, is considered as the driver of product and process innova- 
tion. Almost every innovative activity relates to it. No systematically research has been done about its impact on innovation success and organizational performance. So this paper will address two main research questions: Which capability does a company need in order to achieve innovation success? What impacts does a company's technology selection have on capabilities development, innovation success and organizational performance?

This paper is organized as follows: Firstly, we develop a theoretical model to describe the impact of technological capability and technology management capability on a company's innovation success and organizational performance. Then technology selection is incorporated in this model. Subsequently, the results of an empirical test of the model are discussed. Finally, the managerial implications and further research questions are outlined.

\section{Theory and Hypotheses}

\subsection{The Impact of Technology Selection on Capabilities}

Technology selection is a multi-level decision [17], including technology strategy selection and concrete technology selection. Technology strategy involves both placing greater importance on R \& D and new product development and a desire to be the technological leader in the market. A company selecting a right technology strategy will make more resources available to $\mathrm{R} \& \mathrm{D}$, employ more highly qualified personnel and create a good corporate culture amenable to learning and creativity, which are the basic components of technological capability. Besides, concrete technology selection means the introduction of new and advanced technologies, which are often treated as the source of technological capability. These two points lead to the following hypothesis.

Hypothesis 1: The effect of a company's technology selection has a significant positive impact on the level of its technological capability.

Technology management includes technology resources management, organization management and quality management, while technology strategy determines resources planning, organization structure, quality management mode, so technology management capability will be affected by technology strategy selection. Besides, technology strategy selection determines the emphasis of technology management. For example, if a company selects independent $\mathrm{R}$ \& D strategy or a leading strategy, the key of technology management is technology forecasting, R \& D personnel management, and R \& D risk management. If a company selects imitation strategy or a following strategy, technology management will pay more attention to technology acquisition, especially the cost, speed and the level of technology acquisition. In addition, technology selec- tion is a core technology management process. We summarized these arguments in the following hypothesis.

Hypothesis 2: The effect of a company's technology selection has a significant positive impact on the level of its technology management capability.

\subsection{The Impact of Technology Selection on Innovation Success}

The aim of technology selection is to obtain new knowhow, components, and systems which will help the company to make more competitive products and services and more effective processes [17]. Technology selection means the introduction of new technologies, which can provide opportunities to for both product or service differentiation and new business [18]. Besides, some researchers hold that the right technology strategy selection is vital to a company's innovation [19-20]. We just follow these arguments, and propose a direct relationship between technology selection and innovation success in the following hypothesis.

Hypothesis 3: A company's innovation success is positively correlated with the effect of its technology selection.

\subsection{The Impact of Technological Capability on Innovation Success}

Technological capability means that a company's ability to understand, use and exploit relevant state-of-the-art technology internally [12]. This capability enables a company to add value to its products and processes, and through new product development and the use of new production processes, a company can become a market pioneer. Thus, companies with a high level of technological capability will have greater innovation success than companies with only a low level of technological capability. This leads to the fourth hypothesis.

Hypothesis 4: A company's innovation success is positively correlated with the level of its technological capability.

\subsection{The Impact of Technology Management Capability on Innovation Success}

Many companies play great importance on R \& D through employing more highly qualified personnel, creating a good corporate culture and acquiring more technological resources. However, the results of R \& D are not always fit for the demand of market or the development of the companies, and the innovation performance is not always high. The reason leading to this phenomenon is that the companies don't pay enough attention to its technology management capability. Technology management capability is a kind of dynamic capabilities aiming to explain the way in which a company allocates resources 
and establishes processes for innovation over time, how it generates and deploys its existing resources and processes, and where it obtains new resources [21]. The level of this capability determines the efficiency of technological resources utilization. Several studies have shown that technology management capability exerts great influences on new product development performance [22-24]. These arguments lead to the following hypothesis:

Hypothesis 5: A company's innovation success is positively correlated with the level of its technology management capability.

\subsection{The Impact of Innovation Success on Organizational Performance}

Several studies have examined the role technology innovation plays in the promotion of organizational performance. Robinson's empirical study estimates the impact of product innovation on initial market share, and the results show that the product's advantage relative to competing products has the strongest market share impact [25]. Deng holds that innovation is the main driver of companies' productivity and growth, patent measures reflecting the impact of companies' research on subsequent innovations, and the closeness of research and development to science are reliably associated with the future performance of R \& D-intensive companies [26]. Yamin examined the relationships between organizational innovation and organizational performance in Australian Best Practice Companies, and the results show that organizational performance is related to organizational innovation, which consists of administrative, technical and product innovation [27]. We summarize these arguments in the following hypothesis:

Hypothesis 6: A company's organizational performance is positively correlated with the degree of its innovation success.

The above hypotheses are summarized in Figure 1.

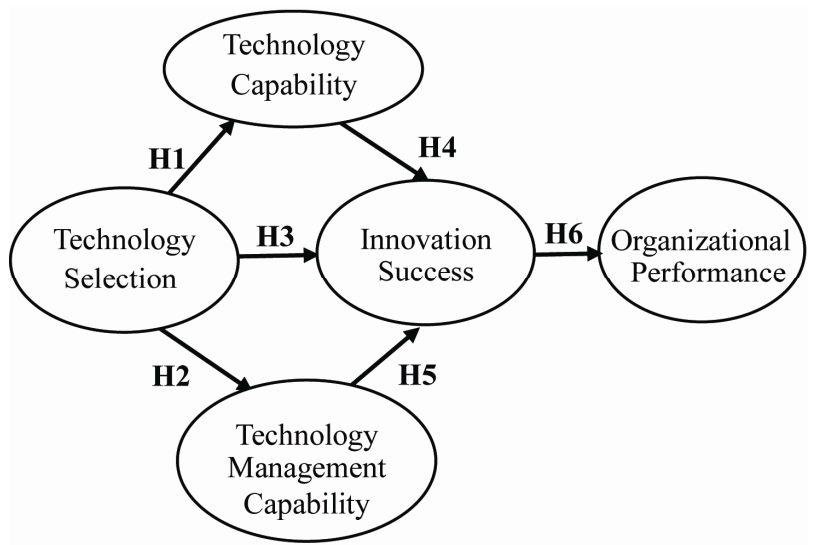

Figure 1. The theoretical model.

\section{The Empirical Study and Results}

\subsection{Sampling and Data Collection}

We selects 120 Chinese companies as the sample, these companies represent a cross-section of various industries in terms of product, process type and characteristics. Industries in the sample included high-tech, manufacturing, chemistry and public utility. The size of these companies ranges between 150 and 2000 employees. 55\% of these companies are medium-sized, $35 \%$ of these companies are small ones, and the other $10 \%$ of these companies are large corporations. Most of the companies have been established for more than 10 years.

We collect the data by means of questionnaire, we send out 360 questionnaires to these companies. Some questionnaires are administered in one-on-one interview formats, while others are distributed to the designated respondents within each company. Most of the respondents are CEOs and managers of R \& D department and market department. After eliminating the questionnaires with which the data are incomplete, the total effective sample size is reduced to 334 , which satisfies the recommendation made by Jaccard and Wan (1996) to achieve power of 0.90 at $\alpha=0.05$.

\subsection{Model Testing}

All constructs are measured using seven-point multiitem scales (see Appendix). Multi-item measures are developed based on Cronbach's alpha. In addition, confirmatory factor analyses are carried out to test each multi-item measure. See the results in Table 1, all the Cronbach's alpha $>0.50$, and all the standardized factor loading $>0.60$, this shows that both the reliability and validity of the measurement model are good.

Table 1. Results of reliability and validity testing.

\begin{tabular}{cccc}
\hline Construct & Indicator & $\begin{array}{c}\text { Standardized } \\
\text { factor loading }\end{array}$ & $\begin{array}{c}\text { Cronbach's } \\
\text { alpha }\end{array}$ \\
\hline Technology & TS1 & 0.64 & 0.67 \\
Selection & TS2 & 0.77 & \\
Technological & TS3 & 0.68 & 0.81 \\
Capability & TC2 & 0.76 & \\
Technology & TC3 & 0.85 & 0.68 \\
Management & TMC2 & 0.73 & \\
Capability & TMC3 & 0.84 & 0.79 \\
Innovation & IS1 & 0.75 & \\
Success & IS2 & 0.81 & 0.76 \\
Organizational & OP1 & 0.64 & \\
Performance & OP2 & 0.63 & \\
\hline
\end{tabular}


Having established the reliability and validity of the measurement model, we will use path analysis to examine the hypothesized structural relationships, that is the structure model testing. We select the following fit indices to assess the adequacy of the model: The ratio $\chi^{2}$ of over the degree of freedom $(d f)$ is used as a descriptive measure of overall fit. Values of this ratio smaller than 5 indicate an acceptable model fit. The goodness-of-fit index (GFI), the adjusted goodness-of-fit index (AGFI) and the comparative fit index (CFI) should exceed a minimum value of 0.9 . For the root mean square error of approximation (RMSEA), values up to 0.08 indicate a reasonable model fit. Data were analyzed using AMOS 6.0. The level of fit in the structural model is indicated by the fit criteria, see Table 2.

From Table 2, we can see $\chi^{2} / \mathrm{d} f=7.03>5$, RMSEA $=0.15>0.08$, these results show that the theoretical model isn't reasonable. Besides, we get the path coefficient of technology selection and innovation success is 0.03 , and the statistics result isn't significant. So we realized that technology selection has no direct impact on innovation success. We delete the direct relationship between technology selection and innovation success in the initial theoretical model. Using AMOS to analyze the modified model again, we get the results in Table 3 .

The results in Table 3 meet all the requirements. We get the path coefficients, which are shown in Figure 2.

\subsection{Data Analysis and Results}

Data are analyzed using AMOS 6.0. The test of the initial model indicates that the relationship between technology selection and innovation success is not significant, that means technology selection has no direct impact on innovation success. Thus, Hypothesis 3 is not supported. We therefore exclude this relationship.

Table 2. Fit testing results of the initial model.

\begin{tabular}{ccccc}
\hline$\chi^{2} / \mathrm{d} f$ & GFI & AGFI & CFI & RMSEA \\
\hline$<5$ & $>0.90$ & $>0.90$ & $>0.90$ & $<0.08$ \\
7.03 & 0.96 & 0.93 & 0.95 & 0.15 \\
\hline
\end{tabular}

Table 3. Fit testing results of the modified model.

\begin{tabular}{ccccc}
\hline$\chi^{2} / \mathrm{d} f$ & GFI & AGFI & CFI & RMSEA \\
\hline$<5$ & $>0.90$ & $>0.90$ & $>0.90$ & $<0.08$ \\
3.46 & 0.95 & 0.92 & 0.94 & 0.05 \\
\hline
\end{tabular}

As shown in Figure 2, the results support Hypotheses 4 and 5. Both technological capability and technology management capability have a significant positive impact on innovation success. We can see that the impacts of both types of capability are about equal. This shows the importance of considering both types of capability as an explanation of a company's innovation success, which depends as much on technological capability as on technology management capability. Technology selection has a strong impact on technological capability and technology management capability. Companies that select right technology strategy and concrete technology will build up greater levels of capability, presumably by making more resources available, developing a supportive corporate culture and employing more highly skilled people. This confirms Hypotheses 1 and 2. Innovation success has a positive impact on organizational performance, which supports the viewpoint that innovation is the source of organizational performance and this confirms Hypothesis 6.

Based on the model as a whole, the following explanation can be given: technology selection supports capabilities development, which, in turn, leads to the achievement of innovation success. Innovation success, coming from converting technology selection into capabilities, plays an important role in the promotion of organizational performance.

\section{Managerial Implications and Further Research}

Through the former theoretical and empirical analysis, we draw the following conclusions: a company's technology selection has no direct impact on innovation success but a significant positive impact on technological capability and technology management capability, which, in turn, have a significant positive impact on innovation success, and innovation success has a positive impact on

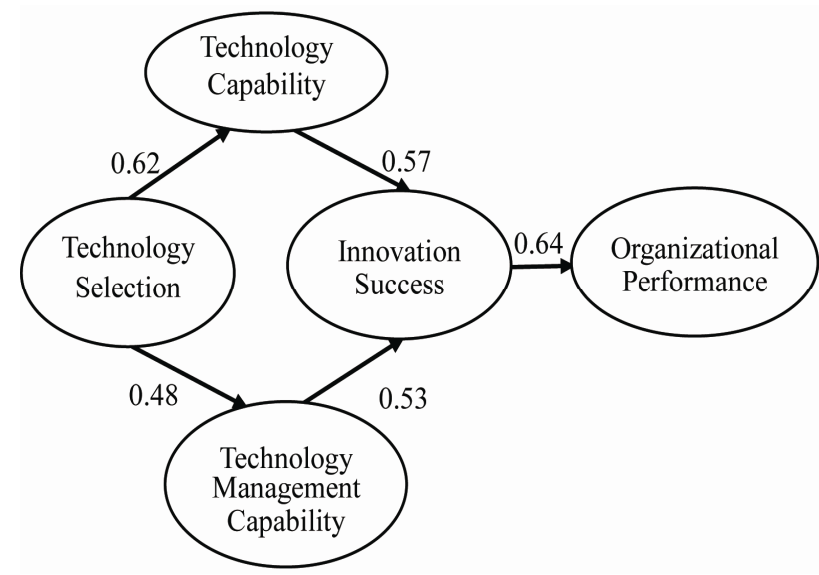

Figure 2. Results of the structural model. 
organizational performance. The indirect effects of technology selection on innovation success and organizational performance are $0.61(0.62 \times 0.57+0.48 \times 0.53)$ and $0.39(0.61 \times 0.64)$. The results and conclusions have two major managerial implications: firstly, technological capability is not only the capability needed by a company to achieve innovation success. Technology management capability can also play an important role in it. Therefore, the company should strive to develop its technology management capability through enhancing technology personnel and equipment management, information management and organization management. Especially the Chinese companies should learn from developed countries to pay increasingly attention to their technology management activities, and promote the level of their technology management capability, through which, technological resources can be managed effectively and efficiently. Secondly, technology selection is not directly related to innovation success. However, it supports the development of technological capability and technology management capability directly and greatly, which, in turn contribute to innovation success. This point is not difficult to understand, only selecting a good technology strategy or an advanced technology is not enough, it must be transformed into technological capability and technology management capability, which will then enable the company to achieve innovation success and promote organizational performance.

There are several questions calling for further research: our study just looked at the role of technology selection and capabilities in innovation success, the focus being on the sources of innovation in terms of internal factors. Other factors, for example, external factors (network competence, social capital) also play a role in a company's innovation success, however, these factors were not included in our model. Besides, we didn't consider about the environmental factors, such as market-specific, industry-specific or environmental characteristics. There is evidence that market and technology dynamics can moderate the impact of technology strategy and capabilities, as well as affect a company's capabilities development. By including these external and moderating factors, we can develop a broader model, which would allow further insights into the mechanisms that achieve innovation success and promote organizational performance.

\section{Acknowledgements}

This work is supported by "the Fundamental Research Funds for the Central Universities” (Grant No. HIT.HHS. 201101) and (Grant No. HIT.NSRIF. 2010085).

\section{REFERENCES}

[1] A. B. Assis, "External Linkages and Technological Inno- vation: Topical Issues,” International Journal of Entrepreneurship and Innovation Management, Vol. 3, No. 2, 2003, pp. 151-175. doi:10.1504/IJEIM.2003.002226

[2] B. Chakravorti, "The Role of Adoption Networks in the Success of Innovations: A Strategic Perspective,” Technology in Society, Vol. 26, No. 2, 2004, pp. 469-482. doi:10.1016/j.techsoc.2004.01.007

[3] C. C. Rogerio, M. G. Fabio and L. M. Gilnei, "Innovation Networks: From Technological Development to Business Model Reconfiguration,” Technology Innovation, Vol. 27, No. 8, 2007, pp. 426-432.

doi:10.1016/j.technovation.2006.08.003

[4] W. G. Biemans, "Managing Innovation within Networks," Routledge, London, 1992.

[5] J. A. Czepiel, "Patterns of Interorganizational Communication and Diffusion of a Major Technological Innovation in a Competitive Industrial Community," Academy of Management Journal, Vol. 18, No. 1, 1975, pp. 6-24. doi:10.2307/255621

[6] C. DeBresson and F. Amesse, "Networks of Innovators: A Review and Introduction to the Issue," Research Policy, Vol. 20, No. 5, 1991, pp. 363-380. doi:10.1016/0048-7333(91)90063-V

[7] H. G. Gemünden, T. Ritter and P. Heydebreck, "Network Configuration and Innovation Success: An Empirical Analysis in German High-Tech Industries,” International Journal of Market Research, Vol. 13, No. 5, 1996, pp. 449-462. doi:10.1016/S0167-8116(96)00026-2

[8] S. L. Brown and K. M. Eisenhardt, "Product Development: Past Research, Present Findings, and Future Directions," Academy of Management Review, Vol. 20, No. 2, 1995, pp. 343-378. doi:10.2307/258850

[9] R. G. Cooper, “The Dimensions of Industrial New Product Success and Failure,” Journal of Marketing, Vol. 43, No. 3, 1997, pp. 93-103. doi:10.2307/1250151

[10] R. G. Cooper and E. J. Kleinschmidt, "Benchmarking the Firm's Critical Success Factors in New Product Development," Journal of Product Innovation Management, Vol. 12, No. 5, 1995, pp. 374-391. doi:10.1016/0737-6782(95)00059-3

[11] K.-H. Tsai, “The Impact of Technological Capability on Firm Performance in Taiwan's Electronics Industry,” The Journal of High Technology Management Research, Vol. 15, No. 2, 2004, pp. 183-195. doi:10.1016/j.hitech.2004.03.002

[12] T. Ritter and H. G. Gemünden, "The Impact of a Company's Business Strategy on Its Technological Competence, Network Competence and Innovation Success," Journal of Business Research, Vol. 57, No. 5, 2004, pp. 548-556. doi:10.1016/S0148-2963(02)00320-X

[13] B. Carlsson and G. Eliasson, "The Nature and Importance of Economic Competence,” Industrial Institute for Economic and Social Research (IUI), Stockholm, 1991.

[14] G. Dosi and D. J. Teece, "Organizational Competencies and Boundaries of the Firm," University of California at Berkeley, Berkeley, 1993. 
[15] F. Malerba and L. Marengo, "Competence, Innovative Activities and Economic Performance in Italian HighTechnology Firms,” International Journal of Technology Management, Vol. 10, No. 4, 1995, pp. 461-477. doi:10.1504/IJTM.1995.025637

[16] R. Sanchez, "Strategic Product Creation: Managing New Interactions of Technology, Markets, and Organizations," European Management Journal, Vol. 14, No. 2, 1996, pp. 121-138. doi:10.1016/0263-2373(95)00056-9

[17] M. Torkkeli and M. Tuominen, "The Contribution of Technology Selection to Core Competencies,” International Journal of Production Economics, Vol. 77, No. 3, 2002, pp. 271-284. doi:10.1016/S0925-5273(01)00227-4

[18] J. Morone, “Strategic Use of Technology," California Management Review, Vol. 31, No. 4, 1989, pp. 91-110.

[19] S. B. Hao and B. Yu, "Research on Impact Mechanism of Technology Strategy on Technology Innovation and Organizational Performance," Studies in Science of Science, Vol. 27, No. 8, 2009, pp. 1263-1270.

[20] G. M. Bao and J. Yang, "The Role of Technological Management in Technological Innovation: Based on the Enterprises in Zhejiang," Studies in Science of Science, Vol. 22, No. 5, 2004, pp. 546-551.

[21] D. Cetindamar, R. Phaal and D. Probert, "Understanding Technology Management as a Dynamic Capability: A Framework for Technology Management Activities," Technovation, Vol. 29, No. 4, 2009, pp. 237-246. doi:10.1016/j.technovation.2008.10.004

\section{Appendix}

1) Technology selection ( $1=$ strongly disagree, $7=$ strongly agree).

TS1 We select the leading strategy in our industry.

TS2 We place high emphasis on R\&D activities.

TS3 We select the most advanced technology in our industry.

2) Technological capability $(1=$ extremely high, 7 = extremely low).

TC1 Personnel capability.

TC2 Equipment capability.

TC3 Organization capability.

3) Technology management capability (1 = extremely high, 7 = extremely low).

TMC1 Resources management capability.

TMC2 Organization management capability.
[22] G. M. Scott, "Critical Technology Management Issues of New Product Development in High-Tech Companies," Journal of Product Innovation Management, Vol. 17, No. 1, 2000, pp. 57-77. doi:10.1016/S0737-6782(99)00012-0

[23] W. W. Wu and B. Yu, "The Impact of Technological Capability on New Product Development Performance: The Moderating Role of Technology Management,” Studies in Science of Science, Vol. 28, No. 3, 2010, pp. 429435.

[24] D. Z. Levin and H. Barnard, "Technology Management Routines That Matter to Technology Managers,” International Journal of Technology Management, Vol. 41, No. 2, 2008, pp. 228-237. doi:10.1504/IJTM.2008.015982

[25] W. T. Robinson, "Product Innovation and Start-Up Business Market Share Performance,” Journal of Management Science, Vol. 36, No. 10, 1990, pp. 1279-1289. doi:10.1287/mnsc.36.10.1279

[26] Z. Deng, B. Lev and F. Narin, "Science and Technology as Predictors of Stock Performance,” Financial Analysts Journal, Vol. 55, No. 3, 1999, pp. 20-32. doi:10.2469/faj.v55.n3. 2269

[27] S. Yamin, A. Gunasekaran and F. T. Mavondo, "Innovation Index and Its Implications on Organizational Performance: A Study of Australian Manufacturing Companies,” International Journal of Technology Management, Vol. 17, No. 5, 1999, pp. 495-503. doi:10.1504/IJTM.1999.002733

TMC3 Quality management capability.

4) Innovation success ( $1=$ strongly disagree, $7=$ strongly agree).

IS1 Compared with our competitors, our product modifications and innovations have a better market response.

IS2 Our production facilities are more advanced than those of our competitors.

5) Organizational Performance (1 = strongly disagree, 7 = strongly agree).

OP1 Compared with our competitors, we occupy a larger market share.

OP2 We achieve a higher sales growth rate than our competitors.

OP3 We achieve a higher profitability than our competitors. 